\title{
Acute Rheumatic Carditis Manifesting As Complete Heart Block At Initial Presentation In A Young Male - A Rare Case Report
}

\author{
P. Praneeth, N. Praveen, A. U. Kiran, N. Vijaya Lakshmi, K. K. Anjani
}

\begin{abstract}
A 26-year male came to the emergency department with a history of syncope along with fever and joint pains of two weeks duration. The electrocardiogram showed a complete heart block (CHB). On further workup, the CHB appeared secondary to Acute Rheumatic Carditis (ARC). The CHB recovered over a week with anti-inflammatory therapy. This case shows that ARC can manifest with a complete heart block and syncope, which is reversible.
\end{abstract}

Index Terms - acute rheumatic carditis; complete heart block; corticosteroids; syncope.

\section{INTRODUCTION}

Acute Rheumatic Fever (ARF) manifests as a delayed autoimmune response to group A beta-hemolytic Streptococcal pharyngitis. It manifests as a generalized inflammatory process involving predominantly the heart and joints, along with the involvement of the central nervous system, the subcutaneous tissue, and the skin. All the manifestations and the cardiac conduction abnormalities except for the carditis (valvular involvement) are selflimiting and leave no significant residual damage. Among the conduction abnormalities, the first-degree atrioventricular block is most common, followed by the second-degree atrioventricular block. The complete heart block (CHB) is rare [1]. ARF commonly affects children between ages 5 and 15 years [1]. The occurrence of ARF as the initial episode in adults is rare. Here we report a case of complete heart block as a manifestation of acute rheumatic carditis at initial presentation in a young male along with the review of the literature.

\section{CASE PRESENTATION}

A 26-year male came from an outside hospital with a history of syncope. Investigations confirmed a complete heart block. A temporary pacemaker from a trans-venous route helped in managing the arrhythmia.

He reported being having fever and joint pains for last

Published on July 1, 2020.

P. Praneeth, CARE Hospitals, India.

(e-mail: pran.omc@gmail.com).

N. Praveen, Osmania General Hospital, India.

(corresponding e-mail: drpraveennagula@gmail.com)

A. U. Kiran, AIG Hospitals, India.

(e-mail: udaykirananne@gmail.com).

N. Vijaya Lakshmi, BMR Hospital, India.

(e-mail: vijayanuthakki84@gmail.com).

K. K. Anjani, CARE Hospitals, India.

(e-mail: kanjanikiranmayi@gmail.com). two weeks. It was associated with chills and rigors. The joint pains were migratory, involving the large joints (ankle, knee, and then the wrist). There were no associated with skin lesions, seizures. Next week, he developed palpitations and shortness of breath, followed by two episodes of presyncope and syncope, for which he visited a local hospital. He was diagnosed having a complete heart block and referred for further management.

Physical examination revealed the following; heart rate of 45 per min (see Fig. 1), blood pressure was 100/70 mm Hg, and fever $39{ }^{\circ} \mathrm{C}$. Intermittent cannon waves in Jugular venous pulse, mildly swollen right wrist, and ankle joints noticed. Cardiovascular system examination revealed a pansystolic murmur at apex.

On investigation, he had a raised total leucocyte count (TLC) 18,000 cells/mm3 with differentials N 86, L 13, M01, E01. He had a hemoglobin of $12.3 \mathrm{gm} / \mathrm{dl}$. The electrocardiogram showed a complete heart block with a heart rate of $45 / \mathrm{min}$, varying ventricular beat morphology between narrow complex and left bundle branch block (see Fig. 1).

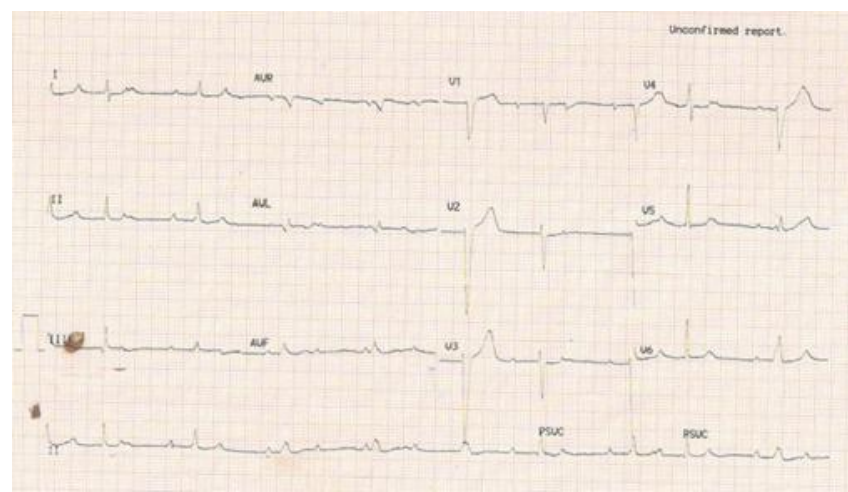

Fig. 1. Electrocardiogram at admission showing complete atrioventricular block ( $p$ waves marching through the QRS complexes) and the ventricular escape rhythm morphology varying between narrow complexes (first two complexes of rhythm strip ) and broad complex of left bundle branch morphology (third and fourth complexes of rhythm strip).

The echocardiogram showed moderate mitral regurgitation (see Fig. 2), mild aortic regurgitation, LV ejection fraction $-55 \%$. There was mild pericardial effusion with no evidence of tamponade. His ESR was $56 / \mathrm{mm}$ in the first hour. His CRP was $36.5 \mathrm{mg} / \mathrm{dl}$, and the ASO titer was $>200$ on sequential samples. His Chest X-ray PA view showed mild right pleural effusion with a normal cardiac silouhette. The positron emission tomography (PET) scan showed no hilar lymphadenopathy and increased cardiac uptake (see Fig. 3). Cardiac Magnetic Resonance imaging showed late gadolinium enhancement (LGE) in the 
epicardium of inferior and left lateral walls and midmyocardium of the middle and distal septum (see Fig. 4). The T2 weighted images showed no myocardial edema normal myocardial perfusion at rest. The patient was negative for leptospirosis, brucella, Lyme disease serology.

The final diagnosis was syncope due to complete heart block in the course of acute rheumatic carditis.

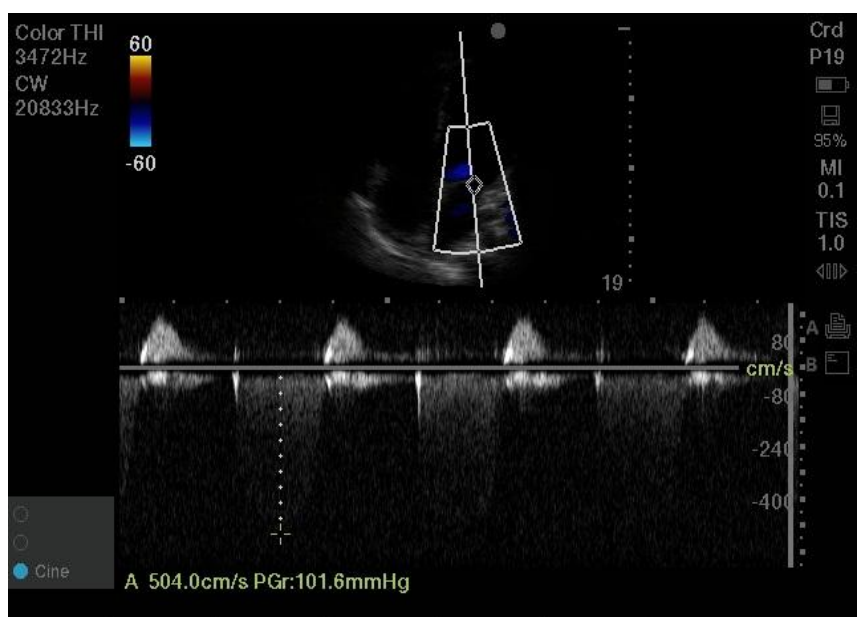

Fig. 2. Apical four-chamber view with both color Doppler and continuous wave Doppler interrogation at the mitral valve, showing mitral regurgitation with a peak velocity of $5 \mathrm{~m} / \mathrm{sec}$ and pressure gradient of $101.6 \mathrm{~mm} \mathrm{hg}$.

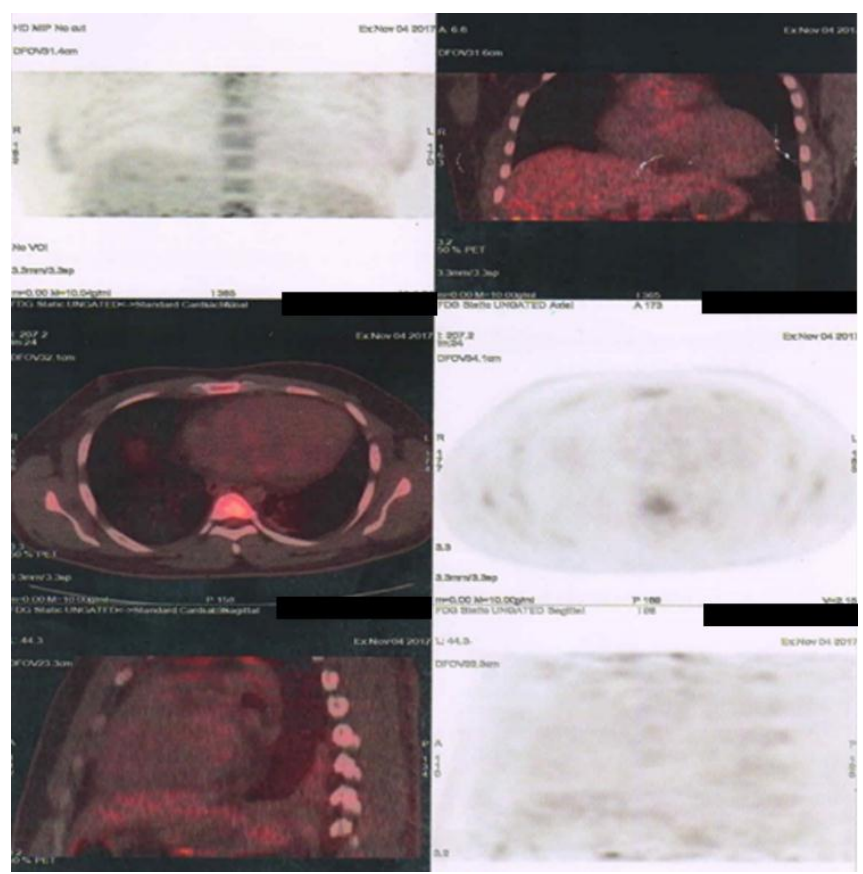

Fig. 3. PET- CT scan of the heart, showing no increased uptake and no hilar lymphadenopathy.

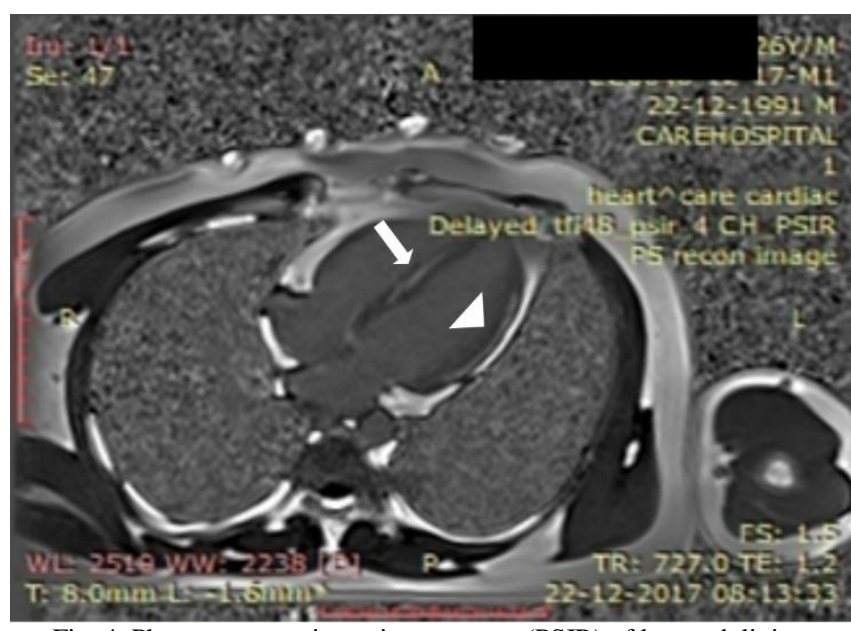

Fig. 4. Phase sequence inversion recovery (PSIR) of late gadolinium enhancement of four-chamber view showing myocardial enhancement of the mid basal septum (white arrow) and epicardial enhancement of lateral wall (white arrowhead).

He received Benzathine Penicillin 12 lakh units deep intramuscularly. Anti-inflammatory therapy with Aspirin 600 qds was started along with prophylaxis for gastric ulcers. Prednisolone $60 \mathrm{mg}$ once daily was given for five days.

The complete heart block improved to first-degree atrioventricular block (see fig.5) in the next five days, and the temporary pacemaker removed. After tapering for two weeks, Prednisolone stopped. The aspirin was decreased to $300 \mathrm{mg}$ qds after two weeks of the resolution of the swelling of joints and continued for the next ten weeks. He received Penicillin prophylaxis once every three weeks for secondary prevention.

At three months of follow up, his electrocardiogram showed a normal PR interval. The echocardiogram showed mild mitral regurgitation, with normal left ventricular function. There was no pericardial effusion.

\section{DISCUSSION}

The electrocardiogram is a valuable investigation in acute rheumatic fever (ARF). The most common finding is a prolonged PR interval. Increased vagotonia is the reason behind prolongation of $\mathrm{PR}$ interval rather than the carditis [1].

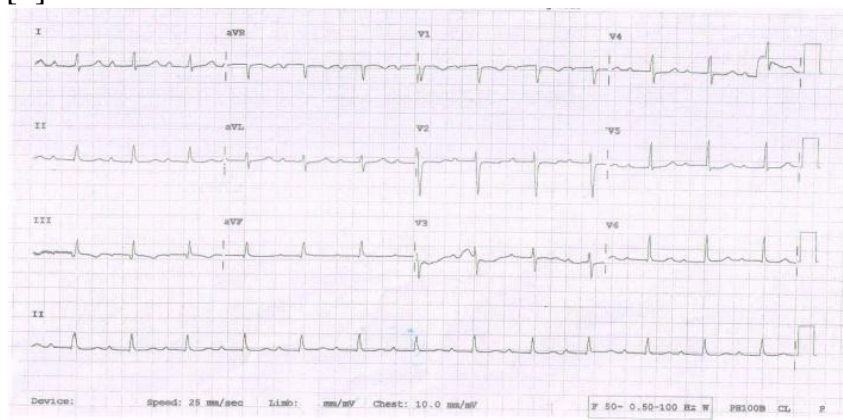

Fig. 5. Electrocardiogram showing sinus rhythm with a prolonged PR interval of $280 \mathrm{msec}$.

The most extensive series of conduction abnormalities in ARF comes from Filberbaum et al. in 1960, who documented rhythm abnormalities from sinus arrest to atrial, junctional tachycardia and complete atrioventricular block [2]. 
In about $50 \%$ cases, the etiology of the complete atrioventricular block is unclear in young (age <55 years). The most common causes found are as a complication to cardiac surgery, congenital atrioventricular block, congenital heart disease, or as a complication of radiofrequency ablation, myocarditis, cardiomyopathies, and inflammatory diseases. In our patient, the presence of fever, increased leukocyte count, and raised CRP levels, led to the consideration of inflammatory disease. The recent onset of symptoms and no previous heart disease rules out the complication of cardiac surgery and congenital etiology [3].

Prolongation of the PR interval seen in almost $70 \%$ of cases $[1,4]$. The second degree AV block - Mobitz type I was the next common abnormality seen with an incidence of $1.5 \%$ [1] - 2.6\% [4]. The complete AV block occurs in $0.6 \%$ of cases [1] and $4.6 \%$ of cases [4]. The documented cases of complete AV block in the literature due to acute rheumatic carditis to date are 31 [5] and frequently seen in the pediatric age group 19/31 (61.2\%) [5]. The AV block was transient, lasting from a few minutes to days, seven patients required permanent pacemaker implantation [5]-[7]. Our patient was 26 years old, had transient $\mathrm{CHB}$ recovered over five days after using prednisolone.

Treatment of the conduction system involvement with ARF is in the same lines as the ARF treatment for carditis. The inflammation of the conduction system leading to the complete heart block hypothesis holds good as the patient improves with anti-inflammatory agents, and the response monitored by a decrease in inflammatory markers like $\mathrm{C}$ reactive protein levels [4]. In patients with symptomatic advance AV block temporary pacemaker placement to be done.

Patients with ARF should receive treatment for Streptococcal infection with or without evidence of pharyngitis. [8]. The treatment includes either oral Penicillin for ten days or a single dose of intramuscular Penicillin [8]. Aspirin in high doses ( $80-100 \mathrm{mg} / \mathrm{kg}$ in divided doses/day) is the drug of choice when there is arthritis. The resolution of the swelling of joints in 48 hours of aspirin is considered the hallmark of ARF [8]. The role of systemic corticosteroids is less clear [8]. Carano and colleagues, as well as Hubail patient, received steroids as part of his treatment regimen [5].

Secondary prevention for recurrent ARF should follow after treatment of the acute phase. Three weekly intramuscular injections are preferred. For patients with a history of carditis (including conduction system involvement), the treatment duration is at least ten years after the initial attack or until age 40 years, whichever is longer. There are some suggestions to receive lifelong prophylaxis in patients with a history of severe carditis [8].

\section{Conclusion}

Acute rheumatic fever manifesting as an initial episode in a young male is rare. Carditis manifests as valvulitis, with mitral being more involved than the aortic. The most common conduction abnormality is the prolongation of PR Interval, and few cases with $\mathrm{CHB}$ are not uncommon. The CHB correlates with the degree of inflammation as monitored by CRP and the ASO titer levels. It is usually transient, though rarely some need permanent pacemaker implantation.

\section{ACKNOWLEDGMENT}

We acknowledge the contribution of Ms.Bhagyalakshmi, physician assistant, the nursing staff of ICCU, the staff of the Radiology Department, CARE Hospitals, Banjara Hills, Hyderabad.

\section{REFERENCES}

[1] M. Clarke, J.D.Keith, "Atrioventricular conduction in acute rheumatic fever," British Heart Journal, vol. 34, pp.472-479, 1972.

[2] M.B. Filberbaum, G.C. Griffith, R.F.Solley, W.H.Leake, "Electrocardiographic abnormality in 6,000 cases of rheumatic fever," California and Western Medicine, vol 64, no.6, pp. 340-346, June 1946

[3] J. R. Resdal, M.K. Christiansen, J. B. Johansen, J. C. Nielsen, H. Bundgaard, H.K. Jensen, "Aetiologies and temporal trends of atrioventricular block in young patients: a 20-year nationwide study," EP Europace, vol 21,no.11,pp.1710-1716, November 2019.

[4] E. Zalzstein, R. Maor, N. Zucker, A. Katz, "Advanced atrioventricular conduction block in acute rheumatic fever," Cardiology in the Young, vol 13, no.6, pp. 491-494, December 2003.

[5] N. Carano, I. Bo, B. Itchana, et al., "Adams-stokes attack as the first symptom of acute rheumatic fever: report of an adolescent case and review of the literature," Italian Journal of Pediatrics, vol 38, no.61,pp.1-5, October 2012.

[6] O.A.A.Ghani, D. Singh, "Acute Rheumatic Carditis: a rare Cause for reversible Complete Heart Block," Hawaii J Med Public Health, vol 74, no.10, pp.341-344, October 2015.

[7] Z. Hubail, I.M. Ebrahim, "Advanced heart block in acute rheumatic fever," .J Saudi Heart Assoc, vol 28, no.2, pp.113-115, April 2016.

[8] M.A. Gerber, R.S.Baltimore, C.B.Eaton, M.Gewitz, A.H.Rowley, S.T.Shulman, K.A.Taubert, "Prevention of rheumatic fever and diagnosis and treatment of acute Streptococcal pharyngitis: a scientific statement from the American Heart Association Rheumatic Fever, Endocarditis, and Kawasaki Disease Committee of the Council on Cardiovascular Disease in the Young, the Interdisciplinary Council on Functional Genomics and Translational Biology, and the Interdisciplinary Council on Quality of Care and Outcomes Research endorsed by the American Academy of Pediatrics," Circulation, vol 119, no.11, pp. 1541-1551, March 2009.

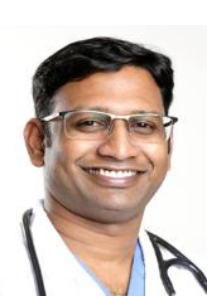

Dr. Praneeth Polamuri has been born and brough up in Hyderabad (15 July 1983). He started his journey of Medicine in 2000 when he joined the prestigious Osmania Medical College, Hyderabad, Telangana. He then joined Nizam's Institute of Medical Sciences, Hyderabad, Telangana in 2007 to get a Master's degree in Internal Medicine. In 2011, he joined back Osmania Medical College to pursue his dream of becoming a Cardiologist. After his studies, he joined CARE Hospital, Banjara Hills, as a Consultant Cardiologist and is providing his valuable services to date.

He has expertise in performing complex interventions like Bifurcations lesions, Chronic total occlusions, and balloon valvotomy, paravalvular leak closure etc. He has been certified as a "trained operator" by Medtronic and MyVal for doing Valve interventions such as Transcatheter Aortic Valve Implantation (TAVI). He specializes in the management of Heart Failure and is one of the members of the Heart Transplant Team at CARE Hospitals.

To quote some of his remarkable publications:

[1] O. A. Naidu, P. Praneeth, Y. V. S. Reddy, R. Srinivas, T. Ashok, and A. Saranag, "Accelerated Atherosclerosis in a Young Female with Familial Hypercholesterolemia," International Journal of Clinical Medicine, vol 5, pp. 541-545, May 2014.

[2] O. A. Naidu, Y. V. S. Reddy, P. Poalmuri, R. Srinivas, (2016) "Common Complication in an Uncommon Disease: Presence of Aortic Regurgitation in Patient with Quadricuspid Aortic Valve," International Journal of Clinical Medicine, vol7, pp.231-235, March2016. 


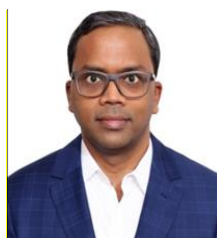

Dr. Praveen Nagula is from Warangal, Telangana (17 December 1982). He started his medical education in 2001 and graduated with M.B.B.S. from Mamata Medical College, Khammam in 2007. He then joined Prathima Institute of Medical Sciences Karimnagar for Post Graduation (M.D.) in General Medicine in 2009. He had done D.M. Cardiology at Osmania Medical College between 2013 and 2016. He teamed up with his co-authors during his DM Cardiology days. With their common interest in Clinical Cardiology, they have published many case reports in various indexed journals.

He has four years of experience and worked as a Jr. Consultant Cardiologist at CARE Hospitals, Banjara Hills, Hyderabad for two years. Presently, working as Assistant Professor in Cardiology, Osmania General Hospital, Hyderabad. He has a keen interest in research and has 20 publications to his credit in various journals. Some of his publications are:

[1] N. Praveen, K. Suneetha, O. A. Naidu, Y. V. Subba Reddy. "Correlation of red blood cell distribution width with the severity of coronary artery disease-A single-center study," Indian Heart Journal, vol.69(6), pp.757-761, April 2017.

[2] N. Praveen, Y. S. Reddy, O. A. Naidu, K. Suneetha. "A clinical study of prognostic significance of left atrial volume index in patients with the acute coronary syndrome," Journal of Indian College of Cardiology, vol 9, pp.186-92, December 2019.

He has been awarded the second best oral paper presentation at CSICON 2015, Chennai. He has been awarded the Sri Krishna Memorial Gold Medal in the year 2015 at TS CSI CON,Hyderabad.

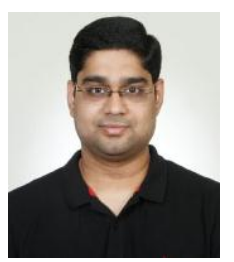

Dr.Uday Kiran Anne is from Guntur, Andhra Pradesh (15 August 1985). He did his MBBS from Rangaraya Medical College,Kakinada. He pursued his MD General Medicine from Guntur Medical College in 2013 and DM Cardiology from Osmania Medical College in 2016.

He has four years of experience. He previously worked as Jr. Consultant Cardiologist at CARE Hospitals and presently working as Consultant Cardiologist in AIG Hospitals, Gachibowli, Hyderabad.

Publications:

[1] O. A. K. Naidu, S. Imamuddin, A. U. Kiran, C. V. Arunavalli, “A Clinical Study of N-Terminal Pro- Brain Natriuretic Peptide as a Predictor of Prognosis in Acute ST Segment Elevation Myocardial Infarction in Comparison with Left Ventricular Ejection Fraction," Indian Journal of Research, vol5, pp. 51-54, October 2016.

[2] C. V. Arunavalli, S. Imamuddin, A. Uday Kiran, "Profile of Congenital Heart Disease as diagnosed by Fetal Echocardiography A Teritiary care experience," Journal of Evidence Based Medicine and Healthcare, vol 2, pp.6656-6661, September 2015.

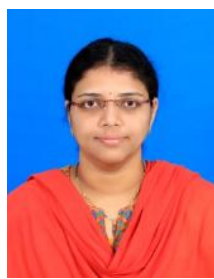

Dr.Vijaya Lakshmi Nuthakki, is from Guntur,Andhra Pradesh (04 April 1984).She got her MBBS from Guntur Medical College in 2008 and MD General Medicine from NRI Medical College, Chinnakakani, Andhra Pradesh in 2013.She pursued her DM Cardiology from Osmania Medical College in 2016.

She worked as Jr Consultant at CARE Hospitals for two years and presently working as Consultant at BMR Hospital,Guntur, AP.

She has been awarded Gold Medal by NTR University of Health Sciences for securing highest marks in DM Cardiology, 2016.

Her publications:

[1] N. Vijayalakshmi, O. A. Naidu, Y. V. S. Reddy, R. Srinivas "Prediction of Cardiotoxicity in Carcinoma Breast Patients Treated with Anthracyclines and Taxanes based on 2D Echocardiography and Biomarkers," Paripex-Indian Journal Of Research, vol 5, October 2016.

[2] Y. V. Subba Reddy, N. VijayaLakshmi, O. A. Naidu, "A study of aetiology, clinical features, ecg, echocardiographic features of cardiac tamponade," Journal of Evidence Based Medicine and Health Care, vol1, pp.205-208, January 2017.

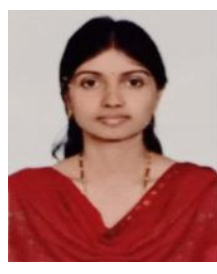

Dr. Anjani Kiranmayi K. is from Hyderabad, Telangana (21 December 1984). She joined MBBS in Osmania Medical College, Hyderabad, in the year 2001. She did her MD in General Medicine from Kakatiya Medical College, Warangal between 2008 2011. She then joined DM Cardiology in Osmania Medical College in Hyderabad, in 2013.

She worked as Assistant Professor in General Medicine at Mamatha Medical College, Khammam and presently working as a Junior Consultant in Care Hospitals, Banjara Hills, Hyderabad since 2019.

Her publications:

[1] K. Suneetha, K. K. Anjani, Y.V. Subba Reddy, "Prognostic value of fragmented QRS in patients with acute coronary syndrome a singlecenter study," Indian Journal of Applied Research, vol6; pp.545-547, October 2016

[2] K. K. Anjani, N. Manasa, N. Praveen, P. Praneeth, A. Uday Kiran, "Nicorandil Induced Oral Ulceration - A Case Report and Review of Literature", International Journal of Innovative Research in Medical Science, vol 2, pp.1491-1493, November 2017.

She has been awarded for best oral paper at Women Cardiology Conference, held at NIMS, Hyderabad in March 2015. 